\title{
SOCIAL PSYCHOLOGY
}

\section{Pilot study of the psychological factors in the professional health of managers}

\author{
Sergey M. Shingaev \\ St. Petersburg Academy of Post-degree Pedagogical Education, St. Petersburg, Russia \\ Corresponding author. E-mail: sshingaev@mail.ru
}

\begin{abstract}
The main research problems and tasks of a new scientific field in Russia-the psychology of professional health - are formulated. A definition of professional health as the abilities of a person successfully to cope with the demands and requirements in a professional environment is offered. A psychological vision for professional health with four basic provisions is proposed. The aim of the research was to study the extent of the influence on the professional health of managers of such psychological factors as systems of values, stress in professional activity, individual and psychological features, strategies for overcoming stressful situations. Data are provided from research conducted in 2002-2012 on managers in Russian companies. Taking part in the research were 651 managers of various organizations in St. Petersburg, Moscow, Yekaterinburg, Veliky Novgorod, and Kharkov. For collecting empirical material on methods of supervision, I used polls, tests, interviews, content analysis, self-reports of participants in training programs, and a method for forming the experiment. In addition I employed psychodiagnostic techniques intended for studying the cognitive, behavioral, and emotional components of health, a technique for revealing the personal potentials (regulatory, communicative, intellectual) of the managers, and also my own techniques. The study positively correlated health with such values as having interesting work, having a happy family life, being financially secure, having an active life, and giving and receiving love. Connections between the behavioral manifestations of type A behavior and the managers' values were revealed. The greatest negative impact on the managers was made by such factors of professional activity as an excessive workload, emotional pressure at work, difficulty in carrying out activity, and insufficient time. Health is important in the structure of the professional activity of managers; it acts as a strategic resource by providing at the least cost efficiency and reliability during all stages of a professional career.
\end{abstract}

Keywords: professional activity, professional health, managers, psychological factors, stress factors 


\section{Introduction}

Today increasing efforts are being made to answer theoretical and applied questions regarding the health of a person at work. The psychology of professional health has been actively developing in Russia and abroad (Christie \& Barling, 2011; Houdmont, Leka \& Sinclair, 2012; Leka \& Houdmont, 2010; Maklakov, 1996; Nikiforov, 2006; Ponomarenko \& Zavalova, 1994; Quick \& Tetrick, 2010; Sinclair, Wang \& Tetrick, 2013). Among the approaches to studying professional health in modern psychology are the psychology of stress in professional activity (Allen, 2002; Atkinson, 1994; Cooper, Cooper \& Eaker, 1988; Lazarus, 1966; Selye, 1979; Vodopyanova \& Starchenkova, 2005) and professional psychohygiene (Kulikov, 2004; Polyakova, 2008).

In 2011 at the Ananyevsky Readings Conference at the faculty of psychology of St. Petersburg State University the first roundtable on the psychology of professional health (PPH) was held. There were discussions on formulation of the concept of professional health $(\mathrm{PH})$, criteria for and indicators of $\mathrm{PH}$, and prospects for the development of $\mathrm{PPH}$.

The trend toward strengthening attention to the field can be traced in the increasing number of publications. The main research problems and tasks in the sphere of scientific interests of PPH (some of which have already been resolved to some extent) are the following:

- definitions of the basic concepts of PPH - especially PH itself - and systematization of its criteria and indicators

- methods of diagnostics, assessment, and PH self-assessment

- psychological factors of PH

- psychological provision of PH (professional self-determination, preparation, adaptation, reliability and safety, longevity)

- $\quad$ stress in professional activity

- professional/emotional burnout and its prevention

- professional harms/diseases/risks and PH

- correction of professional psychoemotional intensity, prevention of professional poststressful frustration

- methodological bases of psychological forecasting of $\mathrm{PH}$

- formation, preservation, and strengthening of $\mathrm{PH}$

- morality of experts in the PH context

- $\mathrm{PH}$ in administrative activity

Prospects for the development of PPH depend on overcoming a disproportionate amount of research concerning the negative side of PH. In Western and Russian psychology about $70 \%$ of research is devoted to stress and professional burnout. In my opinion, it is necessary to increase the amount of research on questions with a positive orientation - the psychological well-being of professionals, health preservation of professionals, satisfaction in a profession, etc. - and also to develop a definition for professional health as now there is no one standard and satisfactory concept. 
$\mathrm{PH}$ most often is understood as the property of an organism to keep a set of compensatory and protective mechanisms that provide working capacity in all conditions of professional activity (Ponomarenko \& Zavalova, 1994). Professional restoration of psychophysiological functions according to the volume and type of professional work recognizes that good $\mathrm{PH}$ is a necessary condition for professional reliability and high performance. I thus offer the following definition: professional health is the ability of a person successfully to cope with the demands and requirements of a professional environment.

In my opinion, a psychological vision for resolving problems in $\mathrm{PH}$ has four basic provisions:

(1) As it is impossible to effect a complete elimination of the influence of negative factors on the health of a working person, it is necessary to look for ways of minimizing losses and reducing the negative influence of the professional environment on health.

(2) At the stage of hiring employees for an organization it is necessary to proceed from reasons of economic efficiency and an assessment of the estimated contribution of a worker to organizational affairs and to select people for a profession in which there are minimum contraindications for them.

(3) It is necessary to increase opportunities for overcoming negative factors in the professional environment and for strengthening the identity of workers so that they are not inevitably affected by the constantly increasing intensity of the most negative factors.

(4) Much research is devoted to questions of occupational diseases and their prevention - they have a vector from illness to the recovery of health. But the way from health to its further maintenance and strengthening is also important. And in this area the acute shortage of both theoretical research and applicable practices is felt.

The profession of manager is one of the ten most promising in the modern world and in the future of Russia. However, managers inevitably face features particular to this profession: systematic psychological, physical, intellectual, and emotional activities. These factors of professional activity can negatively influence the state of health of managers and the level of their working capacity. Thus, health is necessary for managers if they are to effectively implement professional functions, and difficulties with health can seriously complicate their career growth (Kartrayt \& Kuper, 2004).

However, we often come up against a paradoxical situation in which, despite the relevance of health, managers don't pay enough attention to it. Companies are ready to pay tens of thousands of rubles on training personnel in effective sales methods, increasing communicative competence, developing leadership potential, and other programs, but they extremely seldom carry out actions directed at strengthening the $\mathrm{PH}$ of their personnel or train employees in techniques for managing their health.

Data from my poll of top and middle managers in Russian companies (20022010 ) indicate that $47 \%$ did not in any way have a healthy lifestyle at work and often 
did not think about it at all. At the same time every manager without exception declared that health is important for professional activity. To the question "Is the healthy lifestyle of employees supported by the management of your organization?" every third manager answered in the negative.

Abroad, programs for strengthening the $\mathrm{PH}$ of workers are created by the state and corporations. Creation of such mechanisms is in our country in embryo. Health, unfortunately, isn't today a value for managers. Often they do not use even the knowledge and skills that they already possess in this area. The need for research on the psychological factors of the PH of managers is caused by the following circumstances:

- the need to maintain high efficiency in the professional activity of managers as one of the most important professional groups in the Russian economy

- the need to provide healthy, active, and creative lifestyles for managers as citizens of the Russian Federation

- the need to recognize the role of the health of managers as a strategic resource for the development of a company and as a factor in its stability

- the need for orientation toward health as a professionally important quality of the individual and as a way to provide conditions for the market-economy competitiveness of organizations

- the need to form a culture of $\mathrm{PH}$, to reveal mechanisms for creating this culture, to preserve and strengthen health in the course of individual development, and to realize the potential of managers by taking into account genetic, physiological, and psychological characteristics

\section{Method}

Identification of the psychological factors in the $\mathrm{PH}$ of managers was the purpose of my empirical research; these factors are systems of values, stress in professional activity, individual psychological features, and strategies for overcoming stressful situations.

In St. Petersburg, Moscow, Yekaterinburg, Veliky Novgorod, and Kharkov, 651 managers (109 top managers and 542 middle managers) in various organizations took part in the research: 291 men and 360 women aged from 19 to 71 years with a median age of 37 years. When collecting empirical material on methods of supervision, I used polls, tests, interviews, content analysis, self-reports of participants in training programs, and a method for carrying out the experiment. For research on the $\mathrm{PH}$ of managers I used psychodiagnostic techniques intended for studying the cognitive, behavioral, and emotional components of health:

- M. Rokich's modified technique "System of values: purposes and level of their realization", by which 18 values are ranged and the percentage of their level of realization is estimated (from 0 to 100)

- a scale by S. D. Polozhentsev and D. A. Rudnev for identifying type A behavior by measuring these phenomena: ambition, impatience, vigor, hostil- 
ity, insufficiency of time, specificity of behavior, control of emotions, competitive spirit, involvement in work

- S. E. Hobfoll's Strategic Approach to Coping Scale (SACS) questionnaire, "Strategy for overcoming stressful situations," which measures these phenomena: assertive actions, entry into social contact, search for social support, careful actions, impulsive actions, avoidance, manipulative (indirect) actions, asocial actions, aggressive actions

- R. Lazarus's coping test, which measures confrontational coping, distancing, self-checking, searching for social support, accepting responsibility, avoiding flight, planning solutions, revaluating positively

- the AVEM questionnaire by U. Schaarschmidt and A. W. Fischer, "Burnout level in professional activity," which reveals types of managerial behavior in professional situations: G-healthy type, S-economical type, A-type with high probability of the fast development of professional burnout, B-burnout type

- my technique "Factors of professional activity and degree of impact on the manager," which, on the basis of a questionnaire that includes 35 queries, allocates the factors making the greatest impact on managers in the course of the performance of professional activity and estimates the extent of this influence on a 100-mark scale

- my questionnaire "Stress symptoms," which consists of 18 queries for assessing symptoms of physiological, psychological, and behavioral manifestations of stress

- my technique "Ways of relieving stress," a questionnaire that consists of 23 queries assessing how respondents relieve stress

I also used techniques for revealing the personal potential of the managers:

- regulatory potential - a scale of external-internal control by J. Rottera, in which the control locus reveals the reasons for events in the lives of managers and who bears responsibility for them; N.B. Stambulova's modified technique, which includes five scales for measuring strong-willed qualities: commitment, determination, initiative, persistence, self-control, endurance

- communicative potential - G. Ayzenk's technique, which includes 57 questions for measuring extraversion-introversion and neuroticism; A. Megrabyan's technique, which includes 83 questions for measuring empathy, affiliative tendencies, and sensitivity to rejection

- intellectual potential - the CFT-3 test of R. B. Kettel, on the basis of which low, average, and high levels of natural intelligence are allocated; S.M. Makshanov's technique "Verbal efficiency," which estimates a lexicon of the examinee; V.T. Kozlova's modified technique, on the basis of which the lability and flexibility of cogitative activity are measured 
In the research the following procedures for the quantitative analysis of psychodiagnostic data were applied: calculation of averages, standard deviation, determination of values of statistical criteria for establishment of distinctions of averages (criterion of Student's t-test, Mann-Whitney's U-criterion, criterion $\varphi^{*}$-Fisher's transformation), correlation, multiple regression, and Kruskal-Wallis's one-factorial, dispersive procedures analyses. Statistical data processing of the research was carried out by means of the SPSS for Windows 12.0 RU program.

\section{Results and discussion}

\section{Values of managers}

According to the managers surveyed, deterioration of health affects one's values and the realization of a number of vital values. The managers believed that when their health is bad or deteriorating, they lose public recognition (respect of the people around them) and also have fewer opportunities for being creative. At the same time a decrease in their self-assessment of their health forced managers to treat with awe such values as "the beauty of nature, the arts, and having refined experiences."

As a vital value, health was positively correlated by the managers with such values as having interesting work and a happy family, being financially secure, leading an active life, giving and receiving love, and also with having refined experiences. The highest correlation $(p<0.001)$ of the value "Health" was with the values "Interesting work" and "Love (spiritual and physical proximity to a loved one)" (Figure 1).

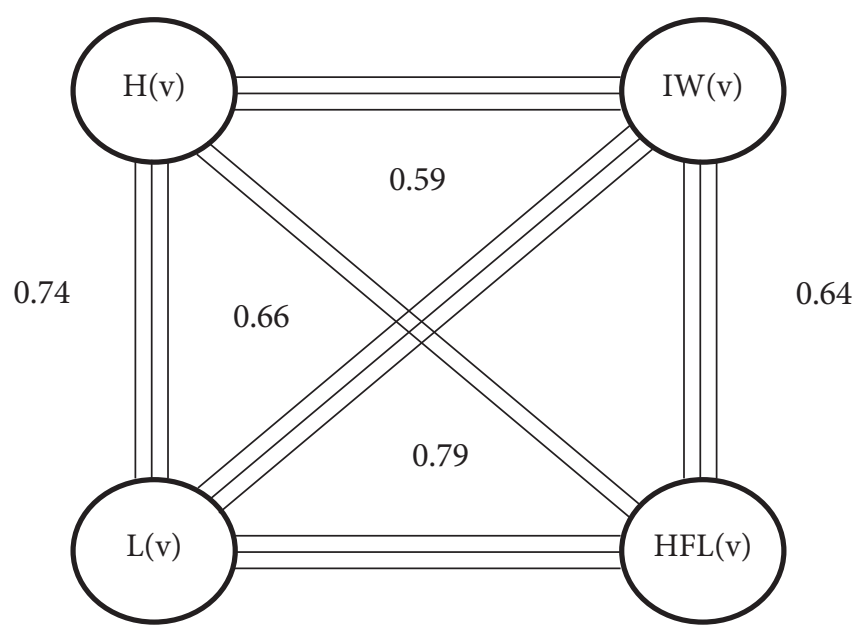

Figure 1. Correlations of the values of managers

Note: H(v) - Health (value); IW(v) - Interesting Work (value);

L(v) - Love (value); HFL(v) - Happy Family Life (value).

$\equiv p<0.001=p<0.01$ 
The level of the availability health was positively correlated by the managers with public recognition (respect of the people around), love, refinement (the beauty of nature, the arts), an active life, and also with such values as freedom and knowledge.

For the married managers the greatest value was "Love (spiritual and physical proximity to a loved one)". For the women the greatest value was "Freedom" $(r=0.31, p<0.001)$.

Among the valuable aspects of life, the managers put health in first place, while on the availability level it took third place.

Analysis of a correlation galaxy testifies to the existence of four basic values that, from the point of view of the managers, had positive correlations among themselves with high significance values $(p<0.001$ and $p<0.01)$ : "Health (physical and mental)," "Interesting work," "Love (spiritual and physical proximity to a loved one)," and "Happy family life."

Analysis of the values of the managers showed that the level of importance and the level of realization of a number of values changed year by year. In 2002-2004 the first five values were as follows: (1) physical and mental health, (2) interesting work, (3) love as spiritual and physical proximity to a loved one, (4) self-confidence, (5) freedom from internal contradictions and independence of actions. In 2009-2010 the values "Interesting work," "Self-confidence," and "Freedom" decreased; they were probably affected by the economic crisis of 2008. At the same time the values "Happy family life" and "Financially secure life" increased. From the point of view of the realization of values "Health" moved from seventh to third place. The managers began to pay attention to their health, to increase personal investments in the maintenance of a healthy lifestyle, and to improve their skills of self-control.

The interrelations of the manifestations by the managers of type A behavior and their values were revealed. A distinction of the ambitious, impatient, vigorous managers with the ability to constrain emotions was their high ranking of the value "Active life" $(p<0.005)$. The managers who highly appreciated the values "Love," "Happy family life," and "Happiness of others" gave a lower ranking to the values "Vigor" ( $p<0.005)$ and "Competitive spirit" $(p<0.05)$; this finding can be explained by their aspiration to concentrate on their private life and the achievement of happiness in their family, goals that compelled them to give less at work. For the managers who highly appreciated "Knowledge" $(p<0.005)$, the main goal was not so much advancing their professional career as having many opportunities to develop and to learn; they ranked the values "Ambition" and "Competitive spirit" particularly low. Those who put in first place the value "Financially secure life" ranked the value "Competitive spirit" highly and exhibited hostility, probably because their aspiration to achieve financial well-being by any means led them to be rigid in their relations with colleagues and partners $(p<0.005)$. The managers who gave a high ranking to "Competitive spirit" also highly appreciated "Interesting work" $(p<0.05)$. The more the managers appreciated "Happiness of others," the lower their hostility toward others $(p<0.05)$. The managers who ranked "Health" high were lesshostile $(p<0.01)$ than those who ranked it low. At the same time managers who considered that they had a high percentage of realization of the values "Health," "Financially secure life," and "Self-confidence" $(p<0.05)$ also were less hostile. 


\section{Stress factors in the professional activity of managers}

The greatest impact on managers is made by such factors of professional activity as an excessive amount of work, emotional pressure at work, difficulty in carrying out activity, insufficient time, and also distracted attention when performing professional activity.

The correlation analysis showed a high degree of interrelationship of these factors of professional activity. The most close connections were among "Danger to life and health, risk," Adverse effect of factors in the physical environment (temperature, noise, vibration, humidity, hunger, thirst, etc.)," "Unfulfilled hopes," "Relationship with fellow workers," "Vital crises," "Difficulty in carrying out activity (deficiency in / incompleteness of information, increased requirements for faultlessness and speed of actions, etc.)," "Lack of necessary professional knowledge and abilities," "Troubles (conflict) with the guide to service," "Bad management," "Relationship with subordinates," "Restrictions on freedom of behavior," "Financial problems," and "Conflicts of personal values with the values declared by the organization."

Perceptions by the managers of stressful factors in professional activity and vital values depended on gender. More of the men than the women were not satisfied with the prospects for an office career and with not-clearly-designated duties at work. They reacted to unfulfilled hopes in their profession more painfully, expressed themselves negatively to management more, and were more affected by problems in the family. The men, unlike the women, appreciated "Self-confidence."

The married managers, unlike the unmarried (divorced, single) managers, perceived more sharply the negative impact of adverse factors of the physical environment at work; situations connected with distracted attention and insufficient time when performing official duties; and also situations that posed hazards to life and health. The married managers, in contrast to the unmarried managers, showed greater concern in regard to the consequences of wrong actions, feared making a mistake more often, and considered themselves insufficiently professional more often. They more often than the unmarried employees perceived as a stressful factor an adverse functional condition in the course of activity performance. Responsibility for their families' well-being sometimes compelled the married managers to be reconciled to the negative factors of professional activity because they felt they were being held hostage by work. The married managers reacted to the stressful factors connected with relationships at work (with colleagues and subordinates) more sharply than did the unmarried managers.

The stress symptomatology of the managers was as follows: $63 \%$ of respondents noted increased irritability; $52 \%$, a periodically arising suppressed mood; $47 \%$, inability to feel drawn to other people; $46 \%$, dream disturbances; $43 \%$, increased arterial pressure; $23 \%$, impossibility of concentrating attention on work; $22 \%$, muscular tension; $22 \%$, appetite and digestion problems; $18 \%$, strong and fast changes of mood; $17 \%$, fatigue and deterioration of quantitative and quality indicators of work; $16 \%$, persistent headaches; $10 \%$, overeating, abuse of smoking, and increase in the consumption of alcohol; 7\%, unmotivated worries on different occasions; $4 \%$, sexual problems. 
Analysis of the matrices of the intercorrelation of the self-assessments of the managers regarding the realization of values and symptoms of stress allows us to draw the following conclusions. The level of realization of the value "Health" was higher the less often the managers abused smoking $(r=-0.24, p<0.001)$. Also those who seldom abused smoking had a high self-assessment of their realization of the values "Public recognition" $(r=-0.20, p<0.05)$, "Knowledge" $(r=-0.24$, $p<0.001)$, "Development" $(r=-0.21, p<0.01)$, and "Creativity" $(r=-0.21$, $p<0.01)$.

The managers with high rates of confidence exhibited less complain of strong headaches $(r=-0.30, p<0.001)$, increased irritability $(r=-0.19, p<0.05)$, suppressed mood $(r=-0.23, p<0.001)$, and unmotivated worries on different occasions $(r=-0.20, p<0.05)$.

\section{Individual and psychological features and specifics of the professional health of managers}

The following is a generalized portrait of the managers from the point of view of PH (results of a scale by S. D. Polozhentsev and D. A. Rudnev to identify type A behavior): vigorous, working under time pressure, involved in work, with a competitive spirit and high ambition, with specificity of behavior and control of emotions at an average level and hostility at a low level (Figure 2).

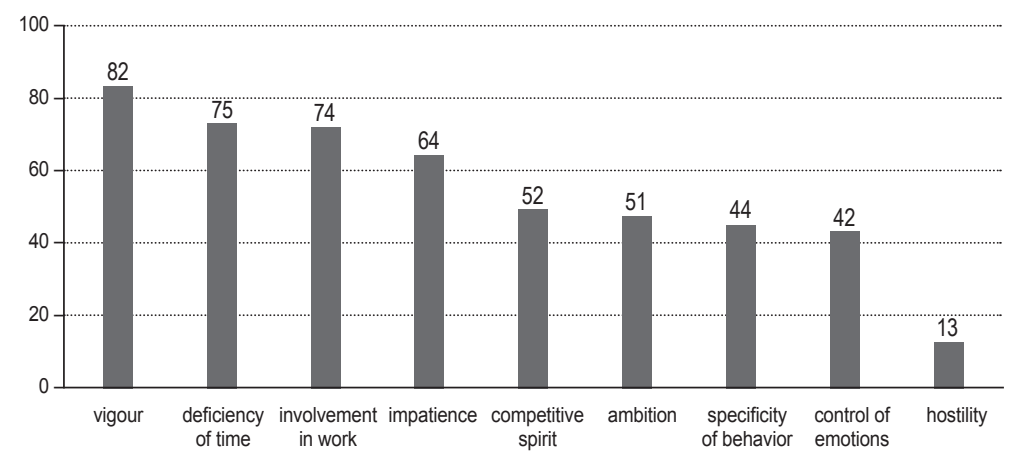

Figure 2. Generalized portrait of the managers according to the results of diagnostics to identify type A behavior (\%)

Most of the managers were aggressive, had large career aspirations, were vigorous, were constantly seeking to make as much money as possible in the shortest period, and were type A people (60\% of respondents); they were distinguished as a whole by a high level of aspiration to achieve success and a high level of competitiveness. Of the managers, $37 \%$ belonged to the category of type B persons; they had a low level of ambition, aggressiveness, and competitive spirit. The remaining $3 \%$ of managers belonged to the mixed-avatars type.

Those managers with a high level of ambition, impatience, vigor, and a tendency toward type A behavior were inclined to increase the length of their working day $(p<0.01)$. There was a significant correlation between specificity of behavior, involvement in work, and duration of the working day $(p<0.001)$. With age 
the managers' ambition, hostility, and competitive spirit significantly decreased $(p<0.05)$.

The managers with high scores on the scale of Type A behavior highly appreciated an "Active life" $(r=-0.18, p<0.05)$, and its realization on a self-assessment was high $(r=0.28, \mathrm{p}<0.001)$.

The analysis of correlations between professional burnout and scales of behavior of type A (by Schaarschmidt and Fischer) showed that the managers who were less involved in work had, as a rule, fewer manifestations of professional burnout $(p<0.005$ for $N=123)$.

The managers with a high level of burnout (type A by the technique of Schaarschmidt and Fischer) used such ways of relieving stress as "Walks," "Travel," and "Extreme sports" ( $p<0.01)$ and used "Communication with relatives," "Sex," and "Humor and laughter" less often $(p<0.05)$.

The interrelations of the personal potentials of the managers with their level of $\mathrm{PH}$ was found. The managers with an internal locus of control observed in themselves such symptoms of stress as dream disturbances, deterioration of the qualitative and quantitative indices of their work, and increased consumption of alcohol; at the same time they paid attention to the muscular tension arising in them more often $(p<0.05$ at $N=132)$.

The managers with an internal locus of control thought highly of "Freedom" as a value and recognized their realization of such values as "Interesting work" and "Financially secure life" ( $p<0.05$ at $N=116)$.

The managers with insufficiently expressed commitment used the coping strategies "Distancing" and "Flight avoidance" less often and the strategies "Planning a solution" and "Positive revaluation" more often. The managers with insufficiently expressed determination realized the coping strategies "Flight avoidance" and "Distancing" less often and the strategies "Planning a solution" and "Positive revaluation" more often. The managers with poorly expressed initiative and independence seldom applied the strategies "Confrontational coping," "Planning a solution," or "Positive revaluation." The managers with pronounced self-control most often used the coping strategies "Planning a solution" and "Positive revaluation."

The interrelation of strong-willed qualities and strategies for overcoming stress (on the SACS) showed that:

- The purposeful managers used the strategy "Avoidance" less often and used "Assertive actions" more often.

- The resolute managers used the strategy "Avoidance" less often.

- The initiative-taking managers used the strategies "Avoidance" and "Aggressive actions" less often.

- The persistent managers use the strategy "Avoidance" less often.

- The supportive managers used the strategies "Avoidance" and "Aggressive actions" less often and more often used "Assertive actions" and "Careful actions."

The neuroticism level of managers was higher the more often they found themselves with such symptoms of a stress as "Persistent headaches," "Unmotivated worries on different occasions," and "Increased irritability" $(p<0.05$, at $N=135)$. 
The introversion of the managers was more expressed the more often they applied "Responsibility acceptance" as a coping strategy. Their neuroticism level was less when they applied the strategy "Planning a solution" ( $p<0.05$, most often used, at $N=27$ ).

The managers with pronounced extraversion used "Sex" and "Extreme sports" as ways of relieving stress more often than the managers with introversion. The managers with expressed neuroticism used "Food" less often and "Travel" more often in order to relieve stress.

The managers with a high level of extraversion gave a leading place to "Active life" in their system of values, and placed "Knowledge" lower as a vital value. The managers with a low level of neuroticism realized such values as "Health (physical and mental)" and "Self-confidence," but fewer than 1 percent of them realized the value "Beauty of nature and art" ( $p<0.05$ at $N=116)$.

The managers who were extroverts had high scores on a scale of type A behavior; they were ambitious, impatient, and vigorous and showed increased hostility toward the people around them, specificity of behavior, and a high level of competitive spirit. These managers most often used such strategies for overcoming stressful situations as "Indirect actions," "Asocial actions," and "Aggressive actions" ( $p<0.05$ at $N=123$ ). The managers who were introverts most often used such strategies for overcoming stressful situations as "Aggressive actions," "Impulsive actions," and "Search for social support" and more rarely used "Assertive actions" ( $p<0.05$ at $N=123$ ).

The managers with a high level of empathy were inclined to use the coping strategy "Positive revaluation"; those with a high level of commitment and a low level of sensitivity to rejection used the coping strategy "Planning a solution" $(p<0.05$ at $N=26$ ).

The managers with highly developed empathy used "Reading" as a way of relieving stress more often; those with highly developed commitment used "Music" more often; those with a high sensitivity to rejection used "Communication with friends" and, more rarely, "Music" ( $p<0.05$ at $N=26)$.

The managers with a high level of empathy thought highly of "health (physical and mental)" and "Love" as values and appreciated "Development" less; they had a higher realization of the value "Knowledge." The managers with a high level of commitment put "Vital wisdom" high in their system of values.

The managers with a low level of sensitivity to rejection highly valued "Ambition," "Competitive spirit," and "Involvement in work" and received generally high scores on a scale of type A behavior.

The managers with high intelligence used the strategy "Careful actions" less often and used "Search for social support" and "Impulsive actions" more often $(p<0.05$ at $N=22)$.

\section{Strategies for overcoming stressful situations}

In stressful situations the managers most often used the strategy "Search for social support" (47\% of respondents) and to a lesser extent used "Aggressive actions" (36\%), "Entry into social contact" (29\%), "Assertive actions" (27\%), "Asocial actions" (24\%), and "Avoidance" (23\%) (Figure 3). 


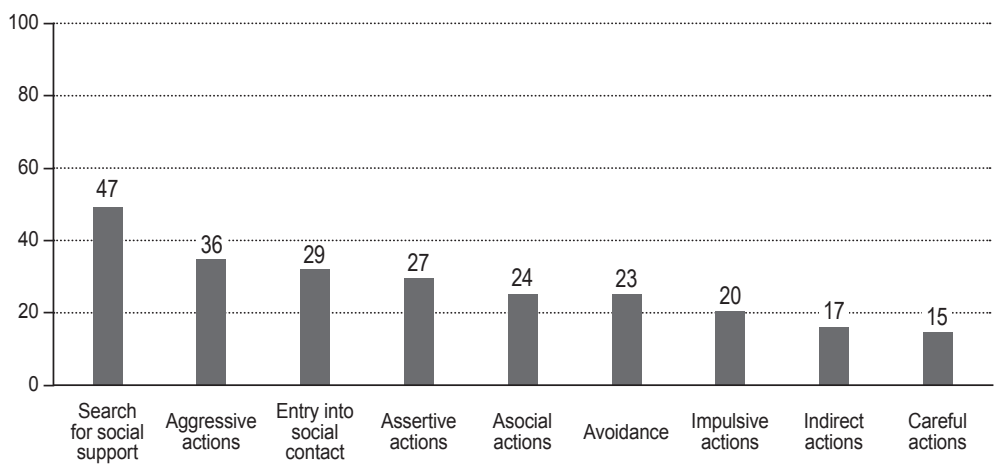

Figure 3. Strategies of managers for overcoming stressful situations (by SACS technique, \%)

In stressful situations the female managers more often than the male managers used the strategies "Entry into social contact," "Search for social support," and "Impulsive actions" ( $p<0.05$ at $N=318)$ and less often used the strategy "Asocial actions" $(p<0.05)$.

The managers belonging to type A much more often $(p<0.01)$ used such strategies as "Entry into social contact," "Indirect actions," "Asocial actions," and "Aggressive actions" and less often used "Avoidance".

In general the managers used such coping strategies as "Self-checking," "Search for social support," "Planning a solution," and "Positive revaluation." They weren't inclined to use confrontation in difficult situations or to avoid the solution of problems.

In fighting stress, the managers used communication with friends (62\% of respondents), humor and laughter (53\%), trips to the country, to nature (49\%), sports activities (42\%), music (38\%), dreaming (38\%), sex (38\%), a hobby (36\%), walks (35\%), communication with relatives (35\%), shopping (34\%), water procedures (a bath, a sauna, a shower, going to a pool) (33\%), travel (30\%), reading (28\%), alcohol intake (28\%), work (26\%), communication with pets $(24 \%)$, viewing of telecasts (23\%), smoking (20\%), food (18\%), extreme sports (14\%), yoga (7\%), medications (5\%).

They less often used aroma procedures, reading entertaining publications (collections of jokes, comic magazines), soaking in a hot bathtub with foam, dancing (more often mentioned by women), "communicating with trees," being entirely alone, going to football matches of a favorite team, searching for information about people who faced more difficult situations than theirs and how they overcame them, receiving a massage, viewing photos of their children on their mobile phones, drinking special teas and grassy infusions, training at seminars, riding, playing computer games, communicating with a child, mountaineering, and pillow beating.

The higher managers scored on a scale of type A behavior, the more they needed support from and communication with relatives $(r=0.22, p<0.001)$. The male managers used alcohol $(r=0.25, p<0.001)$ and sports activities $(r=0.18, p<0.05)$ for stress relief more often than the female managers; the women more charac- 
teristically shopped $(r=0.36, p<0.001)$ and communicated with relatives $(r=0.27$, $p<0.001$ ). The lonely managers (single, divorced, widowers/widows) more often than the managers with families used communication with pets as a way of relieving stress $(r=0.19, p<0.05)$.

\section{Conclusion}

Health as a vital value of the managers in the study was connected with such values as having interesting work and a happy family, being financially secure, leading an active life, giving and receiving love, and also with having refined experiences. In professional activity the greatest influence on the managers was provided by such factors as an excessive workload, emotional pressure at work, difficulty in carrying out activity, insufficient time, and also distracted attention.

Health in the structure of the professional activity of the managers was a strategic resource that allowed them at the smallest cost to pass through all stages of their work both efficiently and reliably. For maintaining their health and fighting against stress at work the managers most often used communication with friends and relatives, humor, walks and trips to the country, sports activities, music, dreaming, sex, a hobby, shopping, water procedures (a bath, a sauna, a shower, going to a pool).

The managers with pronounced self-control most often used the coping strategy "Planning a solution" and "Positive revaluation." The managers who possessed strong-willed qualities (commitment, determination, initiative, persistence, and endurance) used the strategies "Avoidance" and "Aggressive actions" less often and used "Assertive actions" more often. Strong-willed qualities can be considered one of the most important components of good PH in managers.

Prospects for further research lie in detailed study of the psychological factors in the $\mathrm{PH}$ of managers at all stages of their careers, including the stages of professional self-determination, vocational training in a higher education institution, professional adaptation, and leaving the profession.

\section{References}

Allen, D. (2002). Getting things done: The art of stress-free productivity. London: Piatkus Books. Atkinson, J. M. (1994). Coping with stress at work. New York: HarperCollins.

Christie, A., \& Barling, J. (2011). A short history of occupational health psychology: A biographical approach. Washington, DC: Gower.

Cooper, C. L., Cooper, R. D., \& Eaker, L. H. (1988). Living with stress. Harmondsworth, UK: Penguin Books.

Houdmont, J., Leka, S., \& Sinclair, R. R. (2012). Contemporaryoccupational health psychology: Global perspectives on research and practice. Chichester, UK: Wiley. doi: 10.1002/9781119942849

Kartrayt, C., \& Kuper, K. L. (2004). Stress na rabochem meste [Stress in the workplace]. Moscow: Humanitarian Centre.

Kulikov, L. V. (2004). Psychohygiene of the personality. Questions of psychological stability and psychoprevention. St.Petersbrg: Piter

Lazarus, R. S. (1966). Psychological stress and the coping process. New York: McGraw-Hill.

Leka, S., \& Houdmont, J. (2010). Occupational health psychology. Oxford, UK: Wiley-Blackwell. 
Maklakov, A. G. (1996). Bases of the psychological provision of professional health to military personnel. St. Petersburg: St. Petersburg State University.

Nikiforov, G. S. (Ed.). (2006). The psychology of professional health. St. Petersburg: Speech.

Quick, J. C., \& Tetrick, L. E. (2010). Handbook of occupational health psychology (2nd ed.). Washington, DC: APA Books.

Polyakova, O. B. (2008). Psychohygiene and the prevention of professional deformations of the personality. Moscow: NOU VPO MPSI.

Ponomarenko, V. A., \& Zavalova, N. D. (1994). Practical psychology: The problem of the safety of flight work. Moscow: Science.

Selye, G. (1979). Stress without distress. Moscow: Progress.

Sinclair, R. R., Wang, M., \& Tetrick, L. E. (2013). Research methods in occupational health psychology. New York: Routledge.

Vodopyanova, N. E., \& Starchenkova, E. S. (2005). Burning out syndrome: Diagnostics and prevention. St.Petersburg: Piter.

Original manuscript received September 29, 2014

Revised manuscript accepted August 02, 2015

First published online September 30, 2015 